\title{
Application of Gamma Irradiated Textile Wastewater for the Pretreatment of Cotton Fabric
}

\author{
M. A. Rahman Bhuiyan ${ }^{1,2, *}$, M. Mizanur Rahman ${ }^{1}$, Abu Shaid ${ }^{2}$, M. A. Khan ${ }^{3}$ \\ ${ }^{1}$ Department of Applied Chemistry and Chemical Engineering, University of Dhaka, Dhaka-1000, Bangladesh \\ ${ }^{2}$ Department of Textile Engineering, Dhaka University of Engineering and Technology, Gazipur-1700, Bangladesh \\ ${ }^{3}$ Institute of Radiation and Polymer Technology, Bangladesh Atomic Energy Commission, P.O. 3787, Dhaka-1000, Bangladesh \\ *Corresponding Author: arahman@duet.ac.bd
}

Copyright $(2014$ Horizon Research Publishing All rights reserved.

\begin{abstract}
The paper presents a method for reducing the amount of freshwater used in the textile industry, by using gamma irradiated textile wastewater for scouring and bleaching in the pretreatment process of knitted cotton fabric. The wastewater samples were irradiated by gamma radiation doses between 3-12 kGy that resulted in a reduced $\mathrm{pH}$ value of 9 to nearly neutral 7-7.5, and color reduction percentage of $57-90 \%$. Thus, the water becomes appropriate for replacing freshwater in the scouring-bleaching stage of cotton fabric. The performance of the cotton fabric samples were also evaluated after scouring \& bleaching with irradiated wastewater and found similar to those samples processed with freshwater in respect of whiteness, absorbency and weight loss.
\end{abstract}

Keywords Water Pollution, Gamma Irradiation, Wastewater Treatment and Recycling, Freshwater Saving

\section{Introduction}

The textile industries have great significance in terms of economic contribution as well as employment generation in Bangladesh. But this sector is the major source of environmental pollution. Huge amount of water is consumed in several stages to get finished products in a textile processing plant. The wastewater generated in textile processing plants is contaminated with toxic synthetic colorants and various perilous chemicals. Water is used as medium for the processing of textile materials. Nearly 70 to $150 \mathrm{~L}$ water is required for the processing of $1 \mathrm{~kg}$ cotton fabric [1]. In the recent years, in response to a growing demand on the clothing market, the textiles dyeing industry has rapidly grown in Bangladesh. Of the fibers used in the clothing materials worldwide, $48 \%$ are cotton $[2,3]$, of which $20 \%$ are colored by using water soluble, reactive anionic dyes [3]. Their molecules exhibit one or more functional groups capable of forming covalent bonds with cellulose, and are not suitable for recycling [4]. A considerable amount (10-40 \%) of unfixed hydrolyzed dyes remains in the wastewater, resulting in an intensely colored effluent discharges [5], which represents the main pollution source from the textile industry. This causes agonizing problems in Bangladesh, where the factories release their effluents directly into the rivers, canals and water streams, thus polluting the existing surface water sources, and depleting the ground water levels. These aspects endanger the public safety and question the perspective of sustainable development of the textile industry in Bangladesh. Owing to a growing population, the dyeing companies must recover, recycle and reuse part of the water, or they face the shutdown threat [6]. These factories experience the combined pressures of increasing water demand and wastewater treatment costs. Therefore, the treatment and reuse of the wastewater resulted from the textile industry is a subject of great interest for research [7-11].

The color of the textile wastewater is not removed efficiently by ordinary treatment technology. Typical techniques for treatment of wastewater include the classical methods such as adsorption [12-14], coagulation [15, 16], filtration [17] and sedimentation [18]. All these techniques have some degree of effectiveness but all of them generate secondary waste which needs to be tackled further [19]. On the contrary, biological treatment based on activated sludge can efficiently reduce the COD (Chemical Oxygen Demand) but complete color removal is not possible with this technique [20]. Moreover, huge space is required to set up a biological plant. In addition, applications of membrane technologies in textile industries are not yet very common [20]. Again the ultra-filtration techniques prove its success mainly for the recovery of size materials from desizing effluent and indigo dye particles from the discharged dye liquor [21]. The treatment technology that uses ionizing radiation shows promise in fading the color of the dyed textile wastewater [22], without generating secondary waste. The radiation technology methods normally utilize a strong oxidizing species such as ${ }^{\circ} \mathrm{OH}$ radicals which have high electrochemical oxidation potential and cause a sequence of reactions thereafter to break down the macromolecules of 
dye into smaller and less harmful substances [23]. Various active species are produced due to the radiation interaction between gamma rays with water as shown in the equation given below.

$$
\begin{gathered}
\mathrm{H}_{2} \mathrm{O}^{+}+\mathrm{e}^{-} \longrightarrow \mathrm{H}^{\cdot} \mathrm{OH}+{ }^{\cdot} \mathrm{H} \\
\mathrm{H}^{+}+\mathrm{H}_{2} \mathrm{O}+\mathrm{e}^{-} \longrightarrow \mathrm{O}^{\cdot}+\mathrm{e}^{-} \longrightarrow \mathrm{H}^{\bullet}+\mathrm{OH}^{\longrightarrow} \longrightarrow \mathrm{OH}^{+}+\mathrm{H}_{2} \mathrm{O}+\mathrm{e}^{-} \longrightarrow{ }^{\bullet} \mathrm{OH}
\end{gathered}
$$

In the presence of dissolved air or oxygen the per-hydroxyl radical $\left(\cdot \mathrm{HO}_{2}\right)$ is also produced.

$$
\cdot \mathrm{H}+\mathrm{O}_{2} \longrightarrow \cdot \mathrm{HO}_{2}
$$

Generally these species are hydroxyl radical $\left({ }^{\circ} \mathrm{OH}\right)$, hydrogen radical $\left(\mathrm{H}^{*}\right)$, hydrated electron $\left(\mathrm{e}^{-}{ }_{\mathrm{aq}}\right)$, and hydrogen peroxide $\left(\mathrm{H}_{2} \mathrm{O}_{2}\right)$ and so on. [24]. From these products, the most reactive species are hydroxyl radical, hydrated electron. Hydroxyl radical attacks the conjugated double bond of the dye particle and breaks it [25]. Thus the colored dye molecules produce colorless smaller molecules which results the decoloration of effluent.

This study explores the feasibility of reusing textile wastewater for the pretreatment, i.e. scouring and bleaching of cotton fabric after decolorizing by gamma irradiation.

\section{Experimental}

\subsection{Materials}

The wastewater samples were collected directly from the mixing tank of Effluent Treatment Plant (ETP) of Divine Textiles Mills Ltd, Gazipur, Bangladesh. The scouring-bleaching treatment of $100 \%$ cotton plain knit fabric of $120 \mathrm{GSM}$ (gram/meter ${ }^{2}$ ) was performed by adding a mix of the chemical agents: Wetting agent (Imeron PCLF) and Peroxide stabilizer (Stabilizer SOF liquid) from Clariant, Bangladesh, Hydrogen Peroxide $\left(\mathrm{H}_{2} \mathrm{O}_{2}\right)$, Acetic acid $\left(\mathrm{CH}_{3} \mathrm{COOH}\right)$, and Caustic soda $(\mathrm{NaOH})$ from Merck, India, Sequestering agent from Dysin, Bangladesh. All the chemicals were of analytical grade and used as received.

\subsection{Equipments}

The wastewater samples were submitted to gamma rays from a Cobalt-60 radioactive source, in an experimental setting provided in the Institute of Radiation and Polymer Technology (IRPT), Bangladesh Atomic Energy Commission, Dhaka. The water $\mathrm{pH}$ was measured with a digital pH meter Ecoscen, Model 1161795 from Eutech Instruments, Singapore. The color absorbance was measured by using an UV-Vis spectrophotometer T60 from PG Instrument, UK. The scouring \& bleaching was carried out in a Sandolab Infrared lab dyeing machine from Copower Technology Ltd. Taiwan. The reflectance of the bleached textile samples was determined with spectrophotometer Data color, Model 650 from USA. The weight loss of fabric as a result of scouring was measured by digital electronic balance,
Model AV-412 from Transcat, USA.

\subsection{Methods}

\subsubsection{Sample collection and irradiation}

Collected water samples were irradiated in a $500 \mathrm{ml}$ plastic bottle at four different radiation doses $(3,5,8,10$ and $12 \mathrm{kGy}$ ) at room temperature at a dose rate $13 \mathrm{kGy} / \mathrm{h}$ without any further treatment or dilution. The irradiated wastewaters were filtered to remove any coarse materials before using for scouring and bleaching of cotton fabric.

\subsubsection{Determining the efficiency of color removal}

The degree of decoloration was calculated from the decrease of absorbance at maximum absorption wavelength after irradiation as follows [19, 25].

$$
\text { Decoloration }(\%)=\left(\mathrm{A}_{0}-\mathrm{A}_{1}\right) / \mathrm{A}_{0} \times 100 \text {. }
$$

Where, $A_{0}$ and $A_{1}$ are the maximum absorbance in visible area of the textile wastewater before and after irradiation.

\subsubsection{Scouring $\&$ bleaching of cotton textile samples}

$5.0 \mathrm{~g}( \pm 5 \%)$ fabric samples were taken in all the experiment and pretreatment was done according to the recipe given in Table-1

Table 1. Single bath scouring bleaching recipe for all test samples

$\begin{array}{cc}\text { Ingredients } & \text { Amount } \\ \text { Wetting agent } & 1 \mathrm{~g} / 1 \\ \text { Hydrogen peroxide } & 3 \mathrm{~g} / 1 \\ \text { Stabilizer } & 0.5 \mathrm{~g} / 1 \\ \text { Caustic soda } & 4 \mathrm{~g} / 1 \\ \text { Peroxide killer } & 0.4 \mathrm{~g} / 1 \\ \text { Acetic acid } & 1 \mathrm{~g} / 1 \\ \text { Material Liquor Ratio } & 1: 10\end{array}$

The scouring and bleaching of fabric samples was performed by exhaust method. The single bath scouring and bleaching procedure is shown in Figure-1

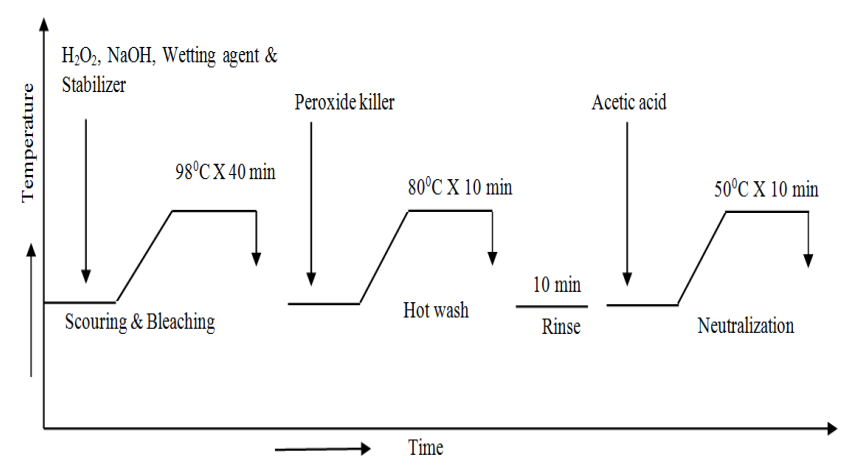

Figure 1. Schematic of the scouring-bleaching sequence applied to cotton fabric

The scouring and bleaching performance was analyzed in terms of their weight loss, absorbency and whiteness. 
Whiteness of the bleached samples was measured in reflectance percentage by using spectrophotometer (Data Color D650). Then the deviation of whiteness was calculated by determining $\Delta \mathrm{E}$ values between fresh water treated sample and wastewater treated samples. Weight loss of all fabric samples were calculated in percentage to identify the damage of the fabric due to scouring and bleaching process.

\section{Results and Discussions}

\subsection{Analysis of $\mathrm{pH}$ Change}

The actual $\mathrm{pH}$ of the reactive dye bath normally lies between 10 to 11 . However, as wastewaters from dyebath mixed with other wastewater from other processes, final $\mathrm{pH}$ of the wastewater in mixing tank had found around 8 to 9 . After irradiation the $\mathrm{pH}$ value of the wastewater decreases from 9 to nearly neutral value (7-7.5) as a result of acid formation due to the breakage of benzene structure [24].

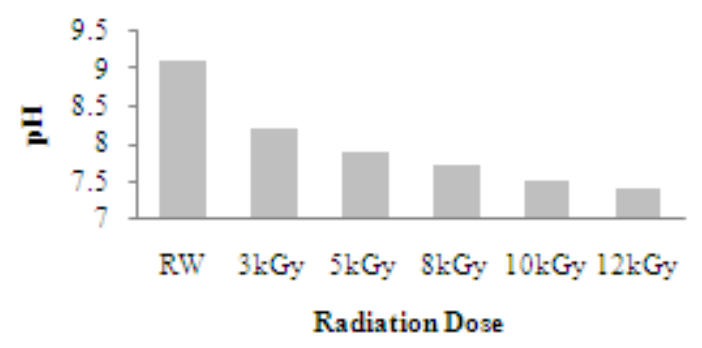

Figure 2. Reduction of $\mathrm{pH}$ from raw wastewater (RW) to irradiated wastewater at different radiation doses

From the study it has been found that, though the $\mathrm{pH}$ of the final wastewater of a textile industry may vary depending on the nature of processing but after irradiation the $\mathrm{pH}$ has decreased with the irradiation doses but the rate of reduction is not significant with increasing radiation doses.

\subsection{Analysis of Color Removal Efficiency}

Color removal efficiency was analyzed by measuring the presence of color in irradiated and un-irradiated wastewater though UV Spectrophotometer. However, color of the textile wastewater differs significantly according to different textile processing, chemicals and dyes. As a result a fixed radiation dose cannot be suggested for all type of textile wastewater. The current research applied 3, 5, 8, 10 and $12 \mathrm{kGy}$ radiation dose on various types of textile wastewater which were collected time to time throughout the year. Then the color reduction percentage was calculated. The color reduction percentage of collected wastewater at different time intervals with above mentioned four radiation doses are given in Figure 3.

From the figure it is clear that color reduction percentages increase according to the gradual increment of radiation dose. The amount of color reduction by radiation depends on color and structure [22] of dye. Wastewater collected for the current investigation was not taken selectively. Therefore water samples were of different types containing different amount of dyestuff shows variation in the reduction of color by irradiation. Furthermore, from the investigation it has also found out that color reduction percentages do not increase significantly after the increment of radiation dose beyond $5 \mathrm{kGy}$. So, considering the cost effectiveness of the process, only $5 \mathrm{kGy}$ irradiated wastewater was selected for the current research purpose to analyze the scouring and bleaching performance.

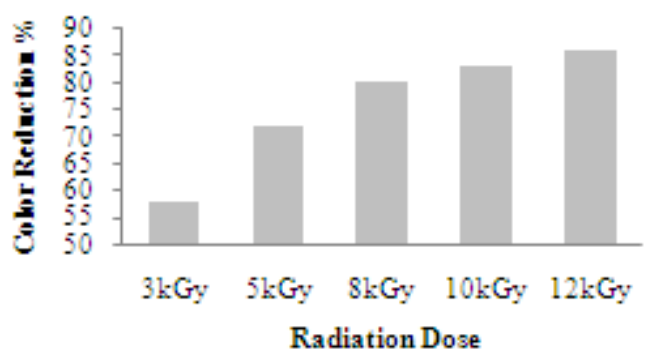

Figure 3. Amount of color reduction of wastewater at different radiation doses.

\subsection{Scouring-Bleaching Performance}

The scouring action of cotton results improved absorbency by the removal of impurities and the bleaching action destroy the natural pigments present in cotton to impart a permanent whiteness. The efficiency of scouring can be measured by measuring the weight loss. Commercially the maximum acceptable limit of weight loss is 4 to $8 \%$ where the lower value than $4 \%$ indicates improper scouring and the higher values than $8 \%$ is a sign of vigorous destruction of the fiber. The bleaching performance was analyzed by measuring the reflectance of white samples. In general a bleached samples having reflectance between 75 to $85 \%$ is acceptable. In the present research, the irradiated wastewater have shown quite acceptable and almost similar performance to the samples which were processed with fresh water in both scouring and bleaching operation. The average weight loss due to scouring was found $6.59 \%$ and $6.39 \%$ for gamma irradiated and fresh water samples respectively whereas the average reflectance of white bleached samples were found to be $76.35 \%$ for irradiated water samples and $78.01 \%$ for fresh water samples. The average results of whiteness and weight loss of scoured-bleached samples found from treated wastewater samples are plotted against corresponding fresh water samples which are shown in figure 4 and 5 .

Figure 5 shows that whiteness of all the bleached samples from irradiated wastewater have reflectance percentage well above the minimum acceptable limit and almost similar to the fresh water samples. Similarly, in the point of view of fabric destruction due to scouring-bleaching, figure 4 illustrates that scouring-bleaching with irradiated water does not impart more fabric destruction and the weight loss limit is within acceptable range. Thus it can be summarized that the gamma irradiated wastewater can be used for the 
scouring and bleaching of cotton goods as an alternative of fresh water for the same purpose.

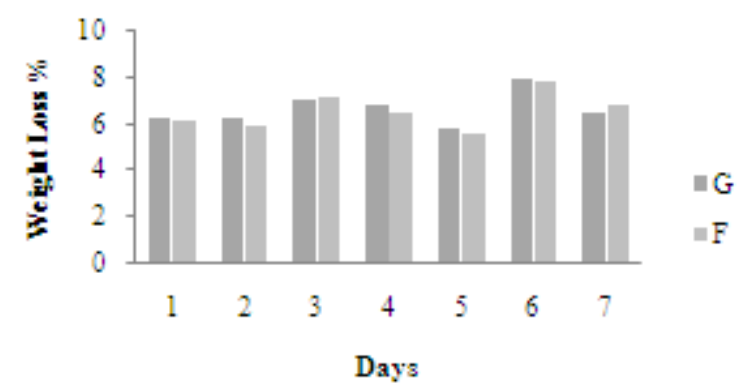

$\mathrm{G}=$ Gamma irradiated water and $\mathrm{F}=$ Fresh water

Figure 4. Average weight loss of scoured cotton fabric samples processed in irradiated and fresh water at different trial dates.

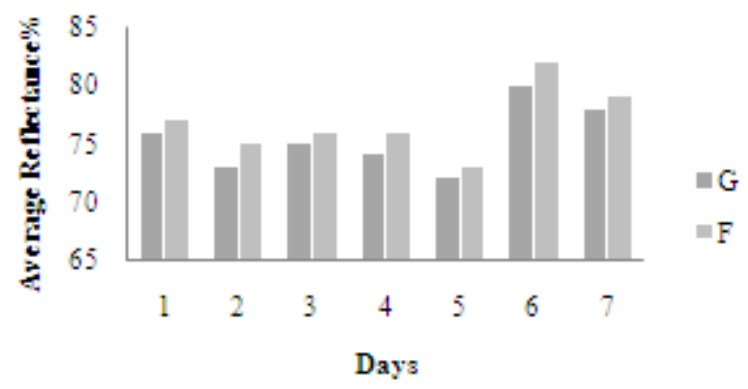

$\mathrm{G}=$ Gamma irradiated water and $\mathrm{F}=$ Fresh water

Figure 5. Average reflectance of white bleached cotton fabric samples processed in irradiated and fresh water at different trial date

\section{Conclusions}

The reuse performance of textile wastewater after gamma irradiation has been investigated. The detail results demonstrated that the absorbency and whiteness of cotton fabric are quite acceptable when the irradiated wastewater is used as a medium instead of fresh water. So, it is concluded that irradiated wastewater can be used satisfactorily for the scouring and bleaching of textile materials.

\section{REFERENCES}

[1] C Allègre, P Moulin, M Maisseu and F Charbit, Journal of Membrane Science, 269 (2006) 15-34.

[2] M Mahbubul Bashar and M Khan, Journal of Polymers and the Environment (2012) 1-10.

[3] AD Broadbent, Basic Principle of Textile Coloration (West Yorkshire, UK: Society of Dyers and Colourists, 2001).

[4] A Erswell, CJ Brouckaert and CA Buckley, Desalination, 70 (1988) 157-167.
[5] P Cooper, So Dyers and Colourists, Colour in dyehouse effluent (Society of Dyers and Colourists, 1995).

[6] C Tang and V Chen, Desalination, 143 (2002) 11-20.

[7] B Van der Bruggen, B Daems, D Wilms and C Vandecasteele, Separation and Purification Technology, 22-23 (2001) 519-528.

[8] I Koyuncu, E Kural and D Topacik, Water science and technology : a journal of the International Association on Water Pollution Research, 43 (2001) 233-240.

[9] SN Gaeta and U Fedele, Desalination, 83 (1991) 183-194.

[10] G Ciardelli, L Corsi and M Marcucci, Resources, Conservation and Recycling, 31 (2001) 189-197.

[11] I Koyuncu, Desalination, 154 (2003) 79-88.

[12] EN El Qada, SJ Allen and G Walker, Chemical Engineering Journal, 135 (2008) 174-184.

[13] BH Hameed, AA Ahmad and N Aziz, Chemical Engineering Journal, 133 (2007) 195-203.

[14] MA Rauf, IA Shehadi and WW Hassan, Dyes and Pigents, 75 (2007) 723-726.

[15] AL Ahmad and SW Puasa, Chemical Engineering Journal, 132 (2007) 257-265.

[16] B Shi, G Li, D Wang, C Feng and H Tang, Journal of Hazardous Materials, 143 (2007) 567-574.

[17] JH Mo, YH Lee, J Kim, JY Jeong and J Jegal, Dyes and Pigents, 76 (2008) 429-434.

[18] ANM Bagyo, H Arai and T Miyata, Applied Radiation and Isotopes, 48 (1997) 175-181.

[19] MA Rauf and SS Ashaf, Journal of Hazardous Materials, 166 (2009) 6-16.

[20] A Bes-Piá, JA Mendoza-Roca, MI Alcaina-Miranda, A Iborra-Clar and MI Iborra-Clar, Desalination, 149 (2002) 169-174.

[21] ASTM, Standard Practice for coagulationflocculation jar test of water (American Society for Testing and Materials, 1995).

[22] D Şolpan and O Güven, Radiation Physics and Chemistry, 65 (2002) 549-558.

[23] N Getoff, Radiation Physics and Chemistry, 54 (1999) 377-384.

[24] ANM Bagyo, W.A.Lindu, S.Sadjirun, E.K.Winarno, E.Widayat, Arayanti and H.Winarno, "Radiation induced degradation of organic pollutants in wastewater" (Jakarta, Indonesia: Center for the application of Isotopes and Radiation, 2001). 145.

[25] MA Rauf, SB Bukallah, A Hamadi, A Sulaiman and F Hammadi, Chemical Engineering Journal, 129 (2007) 167-172. 